\title{
The Design of Control System for Gearless Synchronous Drum-Motor of the Underground Mine Belt Conveyor
}

\author{
Irina Semykina ${ }^{1, *}$, Alexandra Tarnetskaya ${ }^{1}$ \\ ${ }^{1}$ T.F. Gorbachev Kuzbass State Technical University, 650000, 28 street Vesennyaya, Kemerovo, \\ Russian Federation
}

\begin{abstract}
Regarding the current tendency of replacing the geared electric drives with gearless drum motor and substitution of the obsolete induction motors with energy-efficient synchronous motors, the authors consider the difficulties of the high-power permanent magnet synchronous motor and present its model with parameters corresponding to the real belt conveyor electric drive parameters. This paper describes the questions of the vector control system simulation for the synchronous gearless drum-motor of an underground belt conveyor. The control of permanent magnet synchronous motor is realized having regard to rotor angle and random traffic flow. The mechanical system of an underground belt conveyor is represented by the multimass system with the viscoelastic bar. As a conclusion, the article presents the results of the direct torque control system simulation in the speed adjustment mode.
\end{abstract}

\section{Introduction}

The belt conveyors are the most common type of conveyor transport and the most effective method to deliver the coil ore through the mine face. Nowadays, the belt conveyor electric drives averagely consume $25-30 \%$ of whole underground mine general energy consumption [1]. The most commonly used type of single-drum electric drive consists of one or two induction motors, a hydraulic clutch, the massive gear, and brake systems. This type of drive contains a lot of elements and takes up much space in narrow mine tunnels. The induction motor drives mostly are non-controllable, in some cases, the speed control is realized by an operator within two or three control steps. The geared system and hydraulic couplings mostly need maintenance and easily become disabled because of fatigue damages and elastic shocks.

In induction motor drives constantly causes start-up and load-rejection overvoltages, the high start-up currents and pulsating torque that lead to additional tension and slippage of a belt. This mechanical system not only limits rotation power and reduces efficiency, but also has considerable dimensions. In addition to current requirements of safety and energyefficiency, there are the reasons for the improvement of existing types of geared electric drive in accordance with the current tendency in the electric motor industry [2-4].

By reason of inconsistency with new energy efficiency standards of IE, the ABB and

\footnotetext{
*Corresponding author: siyu.eav@kuzstu.ru
} 
Siemens researches had demonstrated that high-torque permanent magnet synchronous motors (PMSM) increasingly apply as electric motors of drum-motors in belt conveyor systems, and just the one PMSM exceeds two induction motors with equal total power [5-6]. The producers of drum-motor suggested the new decisions of gearless drum-motor with PMSM and leakproof body. Also, the speed control of the large underground belt conveyor allows to increase efficiency and durability of belt and pulleys, provides the balanced loading of the conveyor. In view of the above, it needs to decide the next questions:

1. Following to characteristics of the real belt conveyor driving drum design high-torque PMSM for the gearless drum-motor using the finite-element method

2. Select the most appropriate vector control method in the assumption of the requirement to belt conveyor control.

3. The speed control must be realized having regard to the PMSM rotor angle $\theta$ and the traffic flow.

\section{The Modeling of High-Torque PMSM}

Since the gearless drum-motor has no mechanical transmission, the high-torque PMSM must completely produce the required output power, mechanical torque, angle speed and provide a soft operation of the conveyor without cluthes. The multipolar PMSM has a rotor with radial surface neodim magnets and pole tips to provide uniform distribution of magnetic flux in the air gap and protect permanent magnets from demagnetization [7-8]. Simulation of PMSM was performed using the finite-element method in MotorSolve and Magnet environments software by Infolytica.

Table 1. The parameters of the high-torque PMSM model.

\begin{tabular}{|c|c|}
\hline$P$, rated power, $\mathrm{W}$ & 680 \\
\hline$T_{\text {em }}$, rated torque, $\mathrm{kN} \cdot \mathrm{m}$ & 110 \\
\hline$U$, supply voltage, $\mathrm{kV}$ & 60 \\
\hline$n$, rated rotation, $\mathrm{rpm}$ & 1000 \\
\hline$d$, diameter, $\mathrm{mm}$ & 1200 \\
\hline$L$, length, $\mathrm{mm}$ & 101 \\
\hline$J$, moment of inertia, $\mathrm{kg} \cdot \mathrm{m}$ & 0.72 \\
\hline $\cos \varphi$ & 93.8 \\
\hline$\eta$ & 6 \\
\hline
\end{tabular}

The difficulties of control high-power PMSM related to the high coercive force of permanent magnets $(\mathrm{Hc}=1.8 \div 1.9 \mathrm{~T})$. The most of magnetic field lines penetrate the tooth areas of stator core and material is strongly magnetized. As a consequence, in the air gap the upper harmonics occurs, distribution of electromagnetic flux becomes unequal with peaks in the tooth areas [9]. An additional deforming reactive torque appears as cogging torque $T_{c}$ and reduces the non-sinusoidal back-emf in stator windings with high mutual inductions. It is possible to slip at the position when rotor angle $\theta$ is about $30^{\circ}$, thus high-torque PMSM control system needs a position sensor for continuous smooth control signal.

The figure 1 presents the cogging torque non-sinusoidal form resulting by non-loaded 
PMSM electromagnetic torque harmonic expansion, the maximum range of cogging torque is $650 \mathrm{~N} \cdot \mathrm{m}$. At the nominal rate mode with variable loads, the ripples that are presented at electromagnetic torque can amount to $25 \%$, which able to occur of steady self-oscillations along the belt, and as a consequence the alarm conditions and the belt conveyor damage.

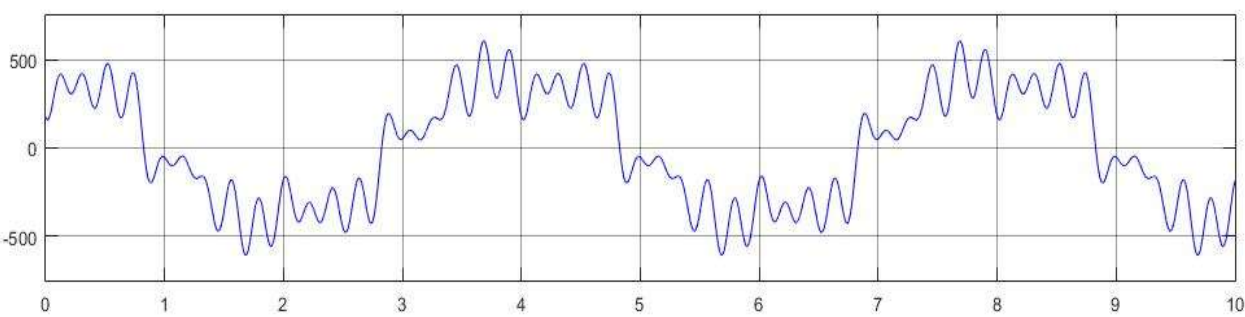

Fig. 1. Low-speed PMSM's cogging torque at no load.

The mathematical model of high-torque PMSM (1) based on the generalized theory of electric drive can be adequately represented as two-phase shunt direct current motor without damper winding model in dq-axes:

$$
\begin{aligned}
& u_{s d}=R_{s} i_{s d}-\frac{d \psi_{s d}}{d t}=R_{s} i_{s d}+L_{s d} \frac{d i_{s d}}{d t}-\omega_{0 e l} L_{s q} i_{s d}, \\
& u_{s q}=R_{s} i_{s q}-\frac{d \psi_{s q}}{d t}=R_{s} i_{s q}+L_{s q} \frac{d i_{s q}}{d t}+\omega_{0 e l} L_{s d} i_{s q}+\omega_{0 e l} \psi p m, \\
& T_{e m}=\frac{3}{2} p_{n}\left[\psi_{p m} i_{s q}+\left(L_{s d}-L_{s q}\right) i_{s d} i_{s q}+T_{c o}\right], \\
& \omega_{0 e l}=\frac{1}{J}\left(T_{e m}-T_{r e s}\right) .
\end{aligned}
$$

According to crossing fields principle, electromagnetic torque contains two components. The first component is major, depends on permanent magnet flux linkage and vertical stator current, and the second is composed of dq-inductivities diminution. For high-torque PMSM additively take the third component $T_{c o}$, the cogging torque.

\section{The Mechanical System of the Belt Conveyor}

In that work is consider the simplified underground belt conveyor system with two-drums electric drive. The real belt conveyor is a difficult multi-elements mechanical system with distributed constants, but it is reasonable to represent it as a five-masses system in which distributed masses of the belt, flow, pulleys, and drums are replaced the definite lumped masses with viscoelastic linkages, the simplified model is presented in Figure 2 [10-11]. 


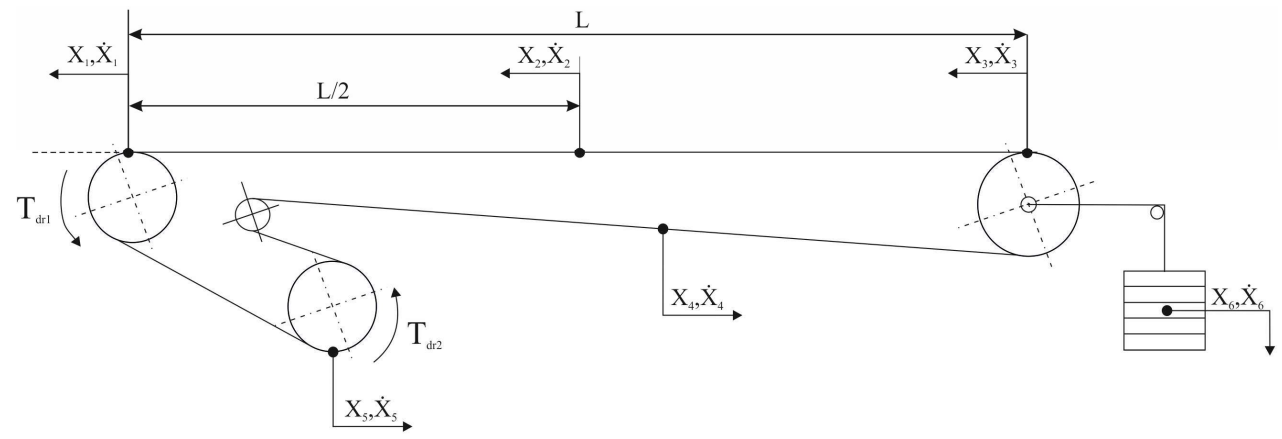

Fig. 2. Mechanic system of underground belt conveyor with two drums and tension unit.

In general terms, the differential equations of the mechanical system in matrix form is:

$$
\begin{aligned}
& \dot{x}=A x+B y, \quad x(0)=0 \\
& y=C x,
\end{aligned}
$$

where $x$ and $\dot{x}$ are matrices respectively of displacements and velocities of lumped masses, $A$ is a system parameters matrix, $B$ is an input matrix, $C$ is an output matrix and $y$ represents a vector of output signals.

\section{The Design of System Control for the Gearless Drum-Motor}

The features of the belt conveyor electric drive operation are high static resistant torque and variable dynamic loads caused by dimensions and masses of mechanic elements, during of grease, splicing of the belt with fine fraction coal, etc. For maintain an unthrottled operation of belt conveyor and steady control, the strict requirements of torque adjustment range, high accuracy of control at low speed and short time of response are applying to electric drive [13].

Through the developing of system control for the gearless drum motor, it does not need to include mechanical elements that significantly simplify the mathematical model of the electric drive system. However, because of lacking such elements like gears and brakes, the system must internally produce soft starting and soft braking of PMSM, it should not be overrejections and high ripples of torque during the transient processes and adjustment of speed.

The comparative analyses of existing vector control systems for slow-moving PMSM [14] concludes that the most appropriate methods are direct torque control (DTC) with spacevector modulation (SVM). The principle of DTC consists of voltage vector selection for simultaneous control of PMSM torque and stator flux linkage. The measured stator currents and inverter voltages are used to estimate the electromagnetic torque and flux linkage. The estimated values of stator flux linkage $\widetilde{\psi}_{S}$ and torque $\widetilde{M}$ are compared with control signals of stator flux linkage $\psi_{s}^{*}$ and torque $M^{*}$ using a comparator. The speed reference block generates reference speed, which depends on input traffic flow and operation mode of the belt conveyor. The space vector modulation based on PWM-principle is used for providing desired values of impulses to inverter [12].

The control system DTC-SVM developed by Matlab Simulink is shown in Figure 3. 


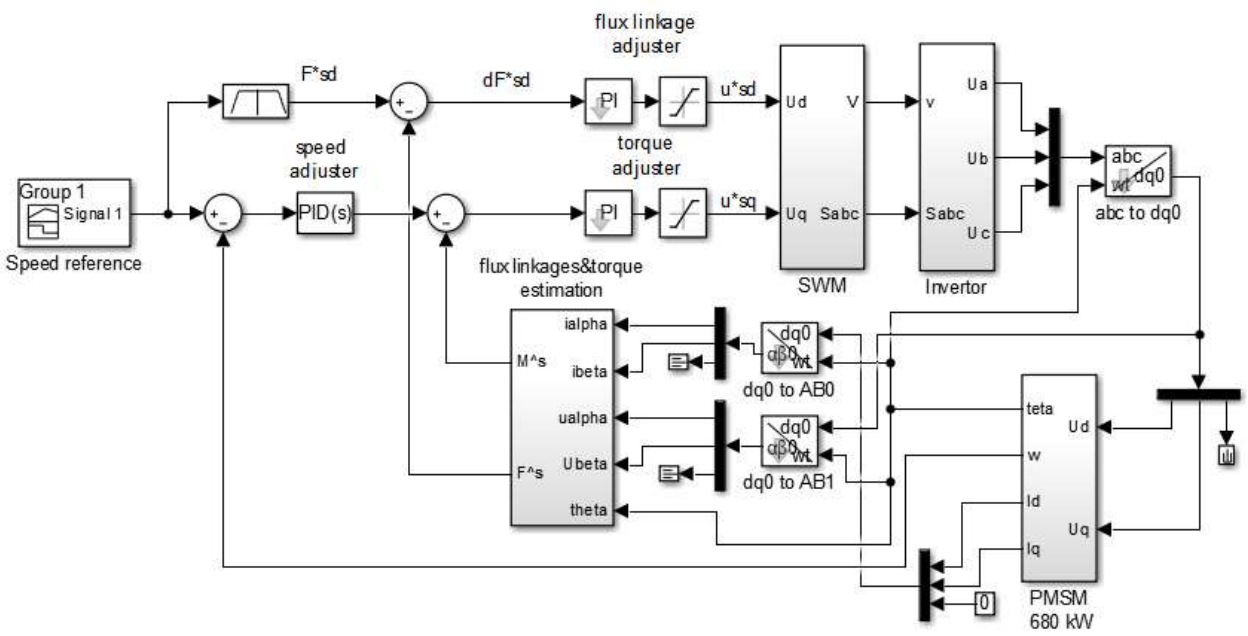

Fig. 3. DTC-SVM control system for gearless synchronous drum motor.

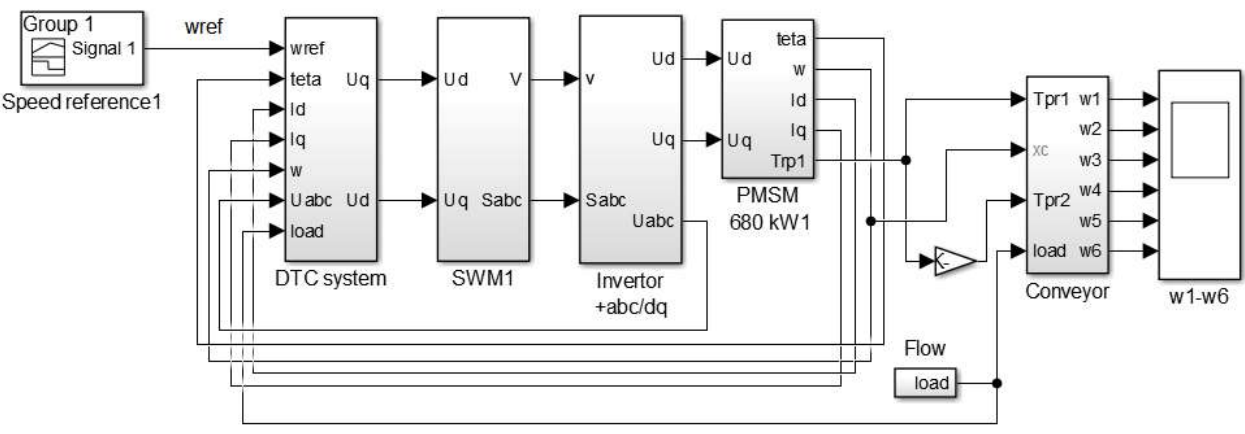

Fig. 4. Control system for two-PMSM electric drive of belt conveyor.

The system control for gearless synchronous drum-motor of the two-drums electric drive of the belt conveyor is presented in Figure 4. The underground belt conveyor traffic flow (load) is represented as a discontinuous process with repeatable periods of load and non-load. The PMSM speed adjustable is developed in function of load range and implemented in four steps.

\section{Conclusion}

This article represents the development of vector control system of the gearless drummotor with PMSM for the underground belt conveyor. The belt speed adjustment implemented in the function of rotor angle and traffic flow. Because of the high ripple of PMSM torque, the direct torque control with space-vector modulation was selected as a control method.

Figures 5 and 6 present the results of two-drums electric drive DTC-SVM-control system simulation. While analyzing the results of figure 5, it can be concluded that during hightorque PMSM under dynamic load and during speed adjustment, the torque ripples caused by strong magnetization of the stator core tooth areas are not surpassing $10-12 \%$ at the transient process and $5-7 \%$ at steady operation mode. 
Figure 6 presents the transient processes along the belt during soft starting, speed variables, and conveyor braking. In that figure the speed adjustments implements on three steps: $\omega_{1}=4 \mathrm{rad} / \mathrm{s}, \omega_{2}=5 \mathrm{rad} / \mathrm{s}, \omega_{3}=\omega_{n}$. The switching steps value can be increased, however, it is not recommended to reduce the lower limit of PMSM working speed. When the PMSM operates at extremely low speeds, it increases the cause of rotor slipping at stopping in a nonsinusoidal magnetic field.

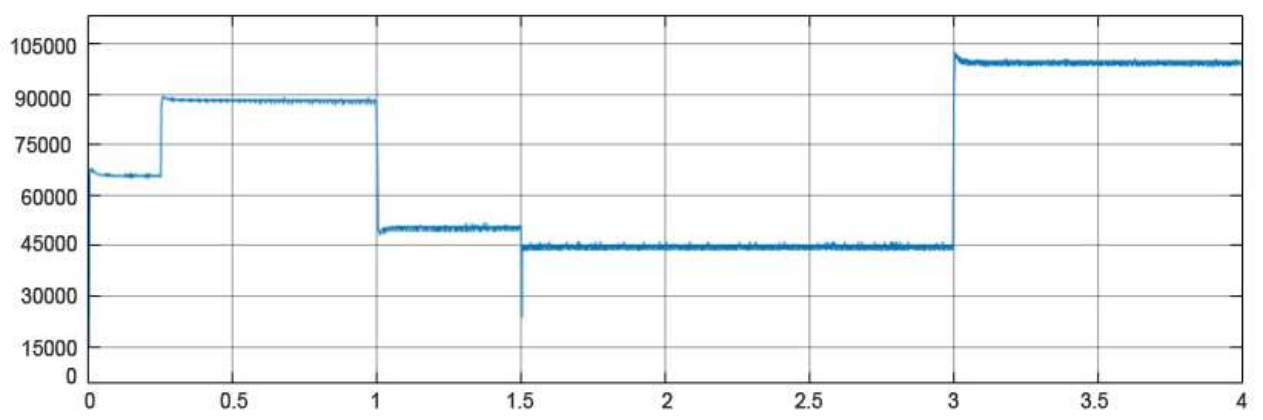

Fig. 5. Results of modeling under dynamic load (torque vs time).

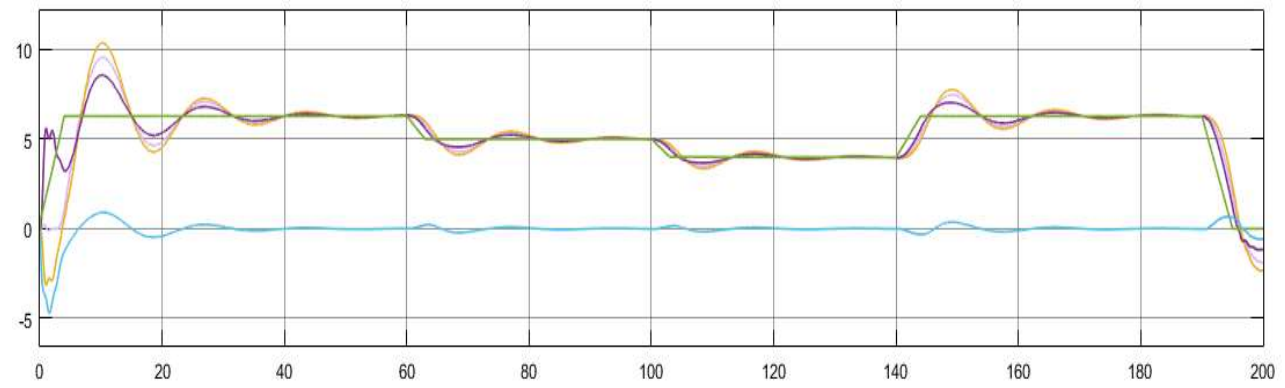

Fig. 6. Results of modeling speed adjusting (angle speed vs time).

As it can be seen in Figure 6, the average duration of transient process under speed switching is 30 seconds, which is not surpass required 5\% and adequate for major changes of traffic flow during 1-10 minutes. Consequently, the developed vector control system of gearless motor-drum with PMSM for underground belt-conveyor is suited to the requirements applied for belt conveyors electric drive control system.

\section{References}

1. INFOMINE Research Group Conveyor Belts in the CIS: Production, Market and Forecast, 3rd Edition (MISiS, Moscow, 2012)

2. B. Rathmann, Mining conveyor systems solution portfolio (ABB - BU-Minerals, Hambueg, 2015)

3. H. Lauhoff, Bulk Solids Handling, 25, 368 (2005)

4. M. A. Alspaugh, Latest Developments in Belt Conveyor Technology (MINExpo, Las Vegas, 2004)

5. A. Kanaris, The Energy Savings \& Performance Gains between two Conveyor Drive Designs (Van der Graaf Drum-motors, Amsterdam, 2016) 
6. M. Combes, Annual Canadian Min. Proc. Oper.Conf. (CMEA, Ottawa, 2014)

7. D. Martínez, Design of a Permanent-Magnet Synchronous Machine with NonOverlapping Concentrated Windings (California Open University, Los Angeles, 2012)

8. M-S Wang, Y-S Kung, H Nguyen, Proc. IMechE, 225, 00120 (2010)

9. Enrique 1 Carrillo, A Modeling and simulation of Permanent magnet synchronous motor drive system (VNHTE, Mayagüez, 2006)

10. Y. N. Kozhubaev, I M Semenov, Fuzzy control system for belt (Leibniz University, Hannover, 2014)

11. V V Dmitrieva, Research and Development of a system of automatic stabilization linear load of the main conveyor (MISiS, Moscow, 2005)

12. A.V. Tarnetskaya, I. Y. Semykina, Zarafshan: Achievements, Problems, Prospects (UGLU, Tashkent, 2017) 